\title{
O Princípio da Lealdade - Provas Obtidas por Meios Proibidos nos Tribunais Internacionais
}

\author{
The Principle of Loyalty - Evidence Obtained in the \\ International Courts Using Prohibited Methods
}

\section{MARIA JOÃO SIMÕES ESCUDEIRO'}

GALILEU - REVISTA DE DIREITO E ECONOMIA - e-ISSN 2184-1845

Volume XIX $\cdot 1^{\text {st }}$ July Julho $-31^{\text {TH }}$ December Dezembro $2018 \cdot$ pp. 78-99

DOI: https://doi.org/10.26619/2184-1845.XIX.2.4

Submitted on July $2^{\text {th }}, 2018$ - Accepted on November 11 $11^{\text {th }}, 2018$

Submetido em 2 de Julho, 2018 . Aceite a 11 de Novembro, 2018

RESUMO Este artigo pretende abordar o princípio da lealdade no âmbito dos meios de obtenção de prova proibidos. As expetativas e anseios que recaem sobre os Tribunais Internacionais são, de tal forma altos, que colocam a Comunidade Internacional de olhos postos nas suas decisões. Neste âmbito, é relevante fazer uma análise das influências dos sistemas da Common Law e da Civil Law nesta matéria, tendo em vista uma compreensão mais abrangente das problemáticas que se levantam. Assim sendo, e tendo em conta que a law in action é mais enriquecedora do que a mera análise substantiva, propomo-nos analisar as decisões do Tribunal Europeu dos Direitos do Homem, mas apenas como precedente daquilo que são e serão as decisões dos Tribunais Penais Internacionais. É sobre estas que primordialmente incidirá o nosso estudo.

PALAVRAS-CHAVE Provas proibidas; Common Law e Civil Law Tribunais Penais Internacionais; interesses da justiça; verdade dos factos.

ABSTRACT This article intends to approach the principle of loyalty within the means of obtaining prohibited evidence. The expectations and aspirations that fall on the International Court are in such high way, which put the international community's eyes on their decisions. In this context, it is relevant to analyze the influences of the Common Law and Civil Law systems, in this area, with a view to a more comprehensive understanding

1 Doutora em Ciências Jurídico-Criminais pela Universidade Católica Portuguesa. Professora Adjunta Convidada do Instituto Superior de Contabilidade e Administração de Lisboa do Instituto Politécnico de Lisboa e Professora Auxiliar do Instituto Superior de Ciências Policiais e Segurança Interna. 
of the problems that can arise. Therefore, and because we think that the law in action is more influent than simply the substantive analysis, we will consider the decisions of the European Court of Human Rights, but only as a precedent of what are and will be the decisions of International Criminal Courts. This is the primarily focus of our study.

KEYworDS Prohibited Evidence; Common Law and Civil Law; International Criminal Courts; interests of justice; truth of the facts.

\section{Princípio da Lealdade}

O princípio da lealdade diz respeito tanto à produção de prova como à condução dos indivíduos no processo. ${ }^{2}$ Como refere Germano Marques da Silva «a lealdade não é uma noção jurídica autónoma, é sobretudo de natureza essencialmente moral, e traduz uma maneira de ser da investigação e obtenção das provas em conformidade com o respeito dos direitos da pessoa e a dignidade da justiça.» ${ }^{3}$ «A atuação desleal como meio de investigação é sempre reprovável moralmente, embora nem sempre sancionada juridicamente.»4

Ao encontro das palavras de Costa Andrade, «os métodos proibidos de prova proscreve a [lei] os atentados mais drásticos à dignidade humana mais capazes de comprometer a identidade e a representação do processo penal... $\gg^{5} \mathrm{Em}$ face destas afirmações, que podemos facilmente adaptar ao contexto internacional, o princípio da lealdade é de suma relevância, logo obrigando a detalhada análise, tendo em consideração que se tratam de matérias pouco consensuais e, por conseguinte, muito discutidas. Tendo este facto como ponto de partida é fundamental iniciarmos esta temática com uma análise à jurisprudência do Tribunal Europeu dos Direitos do Homem (TEDH) que nesta matéria, talvez mais do que em qualquer outra, funcionará como precedente basilar.

O princípio da lealdade encontra-se em correlação com o princípio do acusatório. Sendo certo que no sistema inquisitório o Juiz detém o domínio da audiência de julgamento, cabendo-lhe a sua condução, em muitas situações o Juiz assume a produção da prova e, por isso, a audição e interrogatório das testemunhas. ${ }^{6}$

\footnotetext{
2 Albuquerque, Paulo Pinto de; 2011; p. 55.

3 Silva, Germano Marques da; 2000; pp. 66-67.

4 Idem.

5 Andrade, Manuel da Costa; 2006; p. 209.

6 Idem, p. 204.
} 
É neste contexto que, no âmbito do direito internacional, se abrem as portas a um sistema adversarial, prosseguido pelos Tribunais Internacionais. No âmbito da produção da prova definiu-se um sistema processual de partes.

\subsection{Provas Obtidas por Meios Proibidos}

Nos sistemas da Common Law, os Tribunais não têm regras de exclusão da prova, qualquer prova é admitida em julgamento, desde que tenha relevância. Todavia, os Tribunais têm imposto regras que dizem respeito à voluntariedade com que os testemunhos e depoimentos são prestados. Isto significa que os testemunhos ou depoimentos prestados de forma involuntária ou sob meios coercivos são excluídos dos procedimentos criminais.

Diferentemente, nos sistemas da Civil Law, as provas obtidas por meios proibidos não são necessariamente excluídas dos procedimentos criminais. Os Juízes devem verificar se existiu uma violação das normas criminais e se essa violação colocou em causa os interesses da parte.

Sem embargo, estas características não podem ser aplicadas de forma genérica a todos os sistemas jurídicos pertencentes a uma ou outra família jurídica, porque por exemplo, as normas processuais alemãs nesta matéria são similares ao sistema da Common Law e não ao sistema da Civil Law, como seria de esperar. ${ }^{7}$

\subsubsection{Provas Obtidas por Meios Proibidos no Tribunal Europeu dos Direitos}

\section{do Homem}

O TEDH tem diversas decisões sobre esta temática porque muitos são os casos que chegam a este Tribunal. Importa analisar alguns dos que se nos afiguram como os mais paradigmáticos.

Um desses casos é Jalloh ${ }^{8}$ de 1993, em que quatro polícias à paisana viram o arguido, em duas circunstâncias diferentes, a retirar um saco da boca e entregá-lo a outra pessoa em troca de dinheiro. Acreditando que eram drogas, os polícias detiveram o arguido, mas não encontraram drogas. Pensando que se não agissem de imediato, iriam frustrar a investigação, levaram o arguido para um hospital para tomar uma substância que o fizesse vomitar. Como o arguido não tomou voluntariamente a substância, foi imobilizado pelos quatro polícias e o médico forçou-o a tomá-la através de um tubo ligado ao estômago. Para além disso, o médico injetou-o com uma substância derivada da morfina. Em consequência destas ações, o arguido regurgitou cocaína. O arguido afirmou que durante três dias só comeu 
sopa e que durante duas semanas sangrou pelo nariz. Tendo em conta os factos, o arguido considerou que tinha sido sujeito a tratamento desumano, o que constitui uma violação do art. $3 .^{\circ}$ da $\mathrm{CEDH} .{ }^{9} \mathrm{O}$ TEDH deu razão ao arguido e pensamos que outra não poderia ser a sua decisão.

Num outro caso mais recente, o caso Gäfgen ${ }^{10}$, o arguido também considerou que o art. $3 .^{\circ}$ da CEDH tinha sido violado, porque a sua confissão foi obtida através de meios ilegais. $\mathrm{O}$ arguido raptou um jovem de 11 anos, filho de um banqueiro, e em ordem a descobrir o paradeiro do menor, tendo em conta que a sua vida corria perigo, na hipótese de ainda estar vivo, devido às difíceis condições climatéricas, foi ordenado ao guarda que ameaçasse o arguido com dor, mas de forma a não causar danos físicos. Não obstante, o médico atestou que o arguido tinha sofrido danos físicos. ${ }^{11}$ Conforme os dados apresentados, o TEDH considerou que tinha havido violação, por a confissão ter sido obtida de forma ilegal. Esta decisão do TEDH permite deduzir que a possibilidade de admitir prova indireta em que a prova primária foi obtida de modo ilegal não é admissível porque levaria a um julgamento injusto.

Numa outra decisão do TEDH, proferida no caso Al-Khawaja e Tahery, a opinião de dois dos seus magistrados, Sajó e Karakas, vai no sentido de considerar que se a origem da prova está inquinada, tudo o que daí derive esteja também «doente». Estes magistrados afirmam que é a primeira vez que este Tribunal, sem que se verifiquem quaisquer novas e relevantes razões, diminui o nível de proteção. Sendo assim de grande preocupação o futuro da proteção dos direitos humanos na Europa. ${ }^{12}$

Resta-nos referir um caso muito recente, que foi alvo de destaque na comunicação social, por o indivíduo em causa ser considerado o braço direito de Bin Laden na Europa. O caso Othman ${ }^{13}$ foi analisado pelo TEDH e devido a essa decisão foi impedida a sua extradição do Reino Unido para a Jordânia, por Abu Qatada não ter um julgamento justo na Jordânia, uma vez que algumas das provas usadas contra o clérigo poderiam ter sido obtidas através de tortura. ${ }^{14}$

Ainda dentro do princípio da lealdade, a figura jurídica do salvo-conduto é passível de análise.

A garantia do salvo-conduto foi - e ainda é ocasionalmente - usada para definir a segurança dada pela autoridade de um governo a um desconhecido, para que este possa entrar

9 Idem, §§ 11 a 18.

10 TEDH, Gäfgen v. Germany, Judgment, 1 June 2010.

11 Idem, § 20-22.

12 TEDH, Al-Khawaja and Tahery v. The United Kingdom, Judgment, 15 December 2011, p. 74..

13 TEDH, Othman v. United Kingdom, Judgment, 17 January 2012.

14 Idem, § 25 . 
tranquilamente e voltar a sair do território sobre o qual o respetivo governo tem jurisdição ou controlo. ${ }^{15}$

O salvo-conduto é um documento emitido por autoridades de um Estado que permite ao seu portador transitar por um determinado território, sem o perigo de ser capturado sob alegação de diversos motivos. ${ }^{16}$

Muito recentemente, esta garantia foi alvo de análise pelo TEDH no caso Adamov ${ }^{17}$, tendo sido tomada uma decisão no mínimo polémica e que gerará muita controvérsia. A decisão foi tomada com quatro votos a favor e três votos contra, o que define bem a complexidade da questão em análise e do precedente que pode representar no Direito Internacional Criminal. É por este motivo que faremos uma análise exaustiva deste acórdão, tentando dimensionar as suas incomensuráveis consequências futuras.

O requerente Adamov residia em Moscovo e, devido às suas funções de Ministro da Energia da Rússia, viu ser-lhe instaurado um processo pelos EUA, no ano de 2004. Em 2005, o requerente obteve um visto de autorização do Estado Suíço para poder visitar a filha que residia em Berna. Também em 2005, a filha de Adamov foi acusada de branqueamento de capitais pelo Juiz de Instrução do Cantão de Berna. Adamov foi informado deste facto, mas a convocação oficial do Juiz de Instrução foi feita para a morada da arguida e para o seu advogado. Aquando da sua deslocação privada à Suíça, Adamov foi testemunhar a favor da filha no Tribunal Suíço. Durante o processo, o Tribunal Suíço contactou o Estado da Pensilvânia nos EUA onde decorria o processo contra o requerente. Na decorrência deste contacto, o Ministro da Justiça dos EUA solicitou que fosse feita uma detenção provisória para uma posterior extradição, tal como estava estatuído num acordo realizado entre estes dois Estados. Em consequência, foi emitido um mandado de detenção. O requerente apresentou-se em Tribunal para testemunhar no caso da filha, e ao ser questionado sobre o motivo da sua

15 Um passaporte ou autorização de um estado neutro para as pessoas que estão autorizadas a ir e voltar em segurança e, por vezes, para levar certas coisas em segurança. De acordo com o uso comum, o passaporte é empregado em ocasiões ordinárias para permitir às pessoas circular, sempre que não exista qualquer razão para que elas não devam ir onde lhes aprouver. Diferentemente, o salvo-conduto é o nome dado ao instrumento que autoriza certas pessoas, tais como pessoas procuradas ou sobre as quais existem mandados de detenção, para irem a lugares onde não poderiam ir sem perigo, a menos que exista esta autorização do governo. Salvo-conduto é uma situação que se pode verificar em tempo de conflito internacional ou guerra, onde um estado ou uma das partes no conflito pode conceder um passe ou um documento para garantir que uma determinada pessoa possa entrar e sair do seu território sem medo de ser capturada. $O$ intento é que a pessoa possa responder a questões geralmente fundamentais num outro processo.

16 Um exemplo desta garantia foi o "sealed train" de Lenine, que era um cidadão de um país (Rússia) em guerra com a Alemanha. Lenine foi autorizado a viajar do seu exílio na Suíça através da Alemanha, sem parar, para voltar para a Rússia. Esta situação sucedeu porque era do interesse da Alemanha, porque se acreditava que este facto iria desestabilizar a Rússia. Também na guerra do Vietname esta garantia foi muito utilizada, quer pelas tropas dos EUA, quer pelas tropas do Vietname.

17 TEDH, Case Adamov v. Suisse, 21 Juin 2011. 
deslocação à Suíça, Adamov afirmou que fora por razões particulares. Pouco tempo depois, também a Rússia fez um pedido de extradição do requerente. O requerente foi detido para ser extraditado para os EUA ou para a Rússia que, neste caso, tinha prioridade, mas apresentou um recurso dessa decisão. Por decisão de 9 de junho de 2005, o Tribunal Criminal Federal Suiçco suspendeu a ordem de extradição. O recorrente que se tinha deslocado à Suiça de forma particular, mas que testemunhou, no processo penal contra a filha, afirmou que o aviso de audiência de 02 de maio de 2005 deveria ter sido dirigido de forma oficial e que, por isso, beneficiaria de proteção ao abrigo da cláusula de salvo-conduto, decorrentes da exigência de boa fé, também aplicada a uma pessoa ouvida como testemunha, que não tinha sido convocada formalmente e que se apresentou «espontaneamente» na Suiça para a audiência. Contudo, o recurso de Adamov nos Tribunais Suíços não foi aceite, nem os seus argumentos foram valorizados. É com estes contornos que este caso chega ao TEDH, o requerente considera que foi violado o seu direito à garantia do salvo-conduto, porque não foi inquirido oficialmente para testemunhar e que a sua deslocação se deveu a motivos estritamente privados e comerciais. ${ }^{18} \mathrm{O}$ Estado Suíço não concorda com este argumento e considera que não foi violada a garantia de salvo-conduto. Existem vários textos legais que referem esta garantia, mas parece-nos importante referir o art. 12. ${ }^{\circ}$ da Convenção Europeia de Entreajuda Judiciária em Matéria Penal de 20 de abril de 1959.

O TEDH considerou que Adamov não teria razão e que não tinha sido violada a garantia do salvo-conduto. Argumentou, afirmando que o requerente se deslocou livremente à Suíça, não tendo ido somente para testemunhar no processo da sua filha. Quanto à citação não ter sido realizada para o seu país de origem, o Tribunal afirma que esta foi elaborada quando o requerente já se encontrava na Suíça. Perante este facto, não existia necessidade de cooperação e não se aplicaria o direito inerente à entreajuda judiciária. ${ }^{19}$

Contudo, como supra mencionado, este caso teve três votos vencidos e os três juízes decidiram fazer uma declaração de voto. Estes magistrados consideraram que o Estado Suiço utilizou um «artifício» para fazer o requerente deslocar-se à Suiça e proceder à sua extradição, não podendo este fazer-se valer da garantia do salvo-conduto. Como referem os Magistrados vencidos, há que analisar os factos de forma cronológica e verificamos que o contacto do Juiz de Instrução do Tribunal Suíço foi realizado antes de Adamov sair da Rússia, mas só catorze dias depois é que foi emitido o pedido de extradição por parte dos EUA. Consideram que a citação não foi feita cumprindo os trâmites legais e que, por isso, o requerente estaria protegido por esta garantia. ${ }^{20}$ 
Parece-nos que este acórdão do TEDH abre um precedente muito perigoso, porque ao permitir esta situação corre-se o risco de as testemunhas deixarem de confiar nesta garantia quando se deslocam para depor em Tribunal. Esta decisão de deter Adamov com fundamento numa situação que nos parece, pelo menos, pouco clara, pode levar as testemunhas a temerem que a garantia que lhes é proporcionada não seja cumprida, simplesmente porque foi utilizado um «subterfúgio» para capturar a testemunha.

O futuro o dirá, fica a ressalva do precedente que esta decisão pode representar, porque não podemos esquecer, que muitas testemunhas que se deslocam a Haia, o fazem protegidas por esta garantia. Todavia, se ela deixar de ser de facto «uma garantia» o mais provável é que comecem a ser questionadas as deslocações ao TPI. Como sabemos, os testemunhos feitos presencialmente são de suma importância no âmbito da prova dos julgamentos internacionais. Daí que, na nossa opinião, este seja um precedente no mínimo muito perigoso para a concretização da justiça internacional.

\subsubsection{Provas Obtidas por Meios Proibidos no Tribunal Militar Internacional de Nuremberga e no Tribunal Militar Internacional do Extremo Oriente}

Esta questão só de forma superficial se coloca nestes Tribunais, visto que as Cartas e os Regulamentos Processuais são pouco desenvolvidos e a valoração da prova é analisada caso a caso. A regra fundamental é a de que toda a prova com valor probatório é admissível em Tribunal. ${ }^{21}$ Todavia, esta problemática foi suscitada no caso Hans Fritzsche. O arguido afirmava que a sua confissão era ilegal porque fora conseguida sob tortura e, por isso, não foi considerada em Tribunal..$^{22}$ Hans Fritzsche era responsável pela propaganda do regime. Tendo em conta as provas apresentadas, o Tribunal considerou o arguido não culpado, afirmando que as suas declarações de propaganda ao regime não incitavam o povo alemão a cometer atrocidades contra os povos conquistados. ${ }^{23}$

\subsubsection{Provas Obtidas por Meios Proibidos no Tribunal Penal Internacional para a Ex-Jugoslávia e no Tribunal Penal Internacional para o Ruanda}

De acordo com a Regra 95 dos Regulamentos Processuais de ambos os Tribunais Ad Hoc, a prova não pode ser admitida «se for obtida através de métodos que acarretem dúvidas sobre a sua obtenção ou se a sua admissibilidade for antiética, desde que cause sérios danos à integridade dos procedimentos». 
O Estatuto e Regras Processuais dos Tribunais Ad Hoc não preveem de forma tipificada a proibição de obtenção de prova através de tortura, ou qualquer outro tratamento cruel, desumano ou degradante, mas esta proibição encontra-se bem patente na sua jurisprudência.

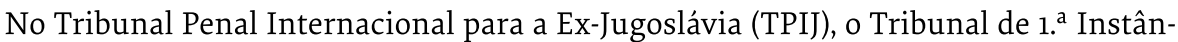
cia esclareceu que, «numa situação em que o arguido tenha sido maltratado, sujeito a tratamentos cruéis, desumanos e degradantes, ou mesmo torturado, antes de ser presente a Tribunal, estes factos podem constituir impedimento legal do exercício da jurisdição do Tribunal. Mas, o Tribunal afirma ainda que podem estar aqui incluídas as autoridades que procederam à detenção ou mesmo os Procuradores investidos de procederem à investigação.» ${ }^{24}$

«Por exemplo, num caso do Tribunal Penal Internacional para o Ruanda (TPIR), o arguido Kabiligi reclamou que tinha sido torturado aquando da sua detenção pelas autoridades do Quénia, na presença dos investigadores do Gabinete do Procurador. Segundo afirma, foi algemado e ameaçado de que regressaria ao Ruanda se não respondesse às questões dos investigadores. $\gg^{25}$

«Todavia, os membros do Gabinete do Procurador não sustentaram nenhuma alegada tortura e a jurisprudência sobre o uso de tortura no contexto internacional é limitada.» Sem embargo, no âmbito do TEDH, existe jurisprudência em que detalhadamente se referem as circunstâncias que poderão levar os atos dos investigadores a constituírem uma tortura ou tratamento degradante. ${ }^{26}$

O que se retira desta regra é que uma prova obtida através de métodos de pouca confiança é inadmissível, e não é necessário verificar-se mais nenhuma condição. A Regra 95 foi alterada em 1995, com base em propostas dos governos dos Estados Unidos da América e do Reino Unido. ${ }^{27} \mathrm{~A}$ admissibilidade ou inadmissibilidade das provas não é mais uma questão de meios, mas de resultados. Antes da alteração, a regra tinha o mérito de desencorajar as violações dos direitos humanos na obtenção da prova ab initio. Tal como se encontra

24 Prosecutor v. Nikolic; Case No. IT-94-2-PT; Decision 9 October 2002; § 114.

25 Prosecutor v. Kabiligi; Case No. ICTR-97-34-I; 6 October 1998. Ver também Prosecutor v. Dokmanovic, Case No. IT-95-13. ${ }^{\text {a-PT; }} 22$ October 1997. In Khan, Karim A. A.; 2010; p. 268.

26 Idem, pp. 268-269.

27 Second Annual Report of the International Tribunal for the Prosecution of Persons Responsible for Serious Violations of International Humanitarian Law Committed in the Territory of the Former Yugoslavia since 1991. U.N. Doc. S/1994/728, 23 August 1995. Com a alteração ver ICTY Doc. No. IT/32/Rev.6, 6 October 1995. O art. 69. ${ }^{\circ}$, n. ${ }^{\circ}$ 7, al. b) do Estatuto de Roma é similar à segunda parte desta regra: «Não serão admissíveis as provas obtidas com violação do presente Estatuto ou das normas de direitos humanos internacionalmente reconhecidas quando: Essa violação suscite sérias dúvidas sobre a fiabilidade das provas; ou A sua admissão atente contra a integridade do processo ou resulte em grave prejuízo deste.» 
plasmado, hoje, na Regra 95, o Tribunal tem em conta todas as circunstâncias relevantes e só exclui a prova que cause graves danos à integridade do processo. ${ }^{28}$

De facto, a Regra 95 não exige uma exclusão automática da prova obtida ilegalmente. ${ }^{29}$ No caso Delalic o Tribunal de $1 .{ }^{\text {a }}$ Instância sustentou que:

«As declarações obtidas de forma não voluntária, ou que parecem obtidas de forma voluntária, mas que na realidade foram conseguidas através de coação, não podem ser admitidas de acordo com a Regra 95».30

Neste mesmo caso, o Tribunal de $1 .^{\mathrm{a}}$ Instância considerou que o incitamento para obter uma confissão não é uma razão suficiente para que a declaração seja excluída. ${ }^{31}$ No caso de crimes sexuais, o alegado consentimento da vítima não é permitido como defesa se estivermos perante ameaças ou situações de coação. ${ }^{32}$ Contudo, se o arguido conseguir provar ao Tribunal de $1 .^{\text {a }}$ Instância que as provas relativas ao consentimento são relevantes e credíveis, as provas sobre o alegado consentimento das vítimas podem ser admitidas, segundo a Regra 96 (iii) de ambos os Tribunais.

Esta decisão é totalmente discricionária e compete ao Tribunal. O Tribunal de $1 .{ }^{\mathrm{a}}$ Instância é composto por Juízes muito experientes, que se encontram perfeitamente aptos para lidarem com questões de prova, inclusivamente para lidar com os problemas da Regra $95 .{ }^{33}$ Somos da opinião que esta é uma temática de tal forma ambígua que não poderia ser totalmente balizada pela lei, daí a necessidade de ser uma decisão discricionária dos magistrados.

Existem dúvidas sobre algumas das matérias que cabem no âmbito de aplicação desta Regra 95. Por exemplo, a questão das comunicações intercetadas durante um conflito armado não são logo excluídas da prova, devem ser admitidas em desafio a esta Regra $95 .{ }^{34}$ Outra situação diz respeito aos depoimentos prestados de forma não voluntária, ou

28 Ver no mesmo sentido: Prosecutor v. Zigiranyirazo, Case No. ICTR-2001-73-T, 29 November 2006, § 13; Prosecutor v. Bizimungu Casimir et al., Case No. ICTR-99-50-T, 1 November 2006, § 12; 4 December 2003, § 29; Prosecutor v. Brdanin, Case No. IT-99-36-T, 3 October 2003, § 61.

29 Ver no mesmo sentido: Prosecutor v. Zigiranyirazo, Case No. ICTR-2001-73-T, 29 November 2006, § 13; Prosecutor v. Bizimungu Casimir et al., Case No. ICTR-99-50-T, 1 November 2006, § 12; Prosecutor v. Brdanin, Case No. IT99-36-T, 3 October 2003, § 54.

30 Prosecutor v. Delalic et al., Case No. IT-96-21, 2 September 1997, § 41.

31 Ibidem, § 55 .

32 De acordo com a Regra 96 (ii) (B) de ambos os Tribunais Ad Hoc: «No caso de crimes sexuais... o alegado consentimento não é admissível se a vítima... tiver sido sujeita a ameaças ou tiver razões para temer violência, detenção ou coação psicológica».

33 Prosecutor v. Milosevic, Case No. IT-02-54-T, 9 June 2005, p. 5.

34 Prosecutor v. Brdanin, Case No. IT-99-36-T, 3 October 2003, § 53. 
seja, testemunhos obtidos através de meios coercivos. Esta prova não pode ser admitida de acordo com a regra referida. Se existem indícios de que foi utilizada coação na obtenção do depoimento, o ónus da prova recai sobre a parte que pretende ver a prova admitida, tendo de provar que o depoimento foi totalmente voluntário. 35

Ainda neste contexto, é difícil imaginar uma situação em que seja violado o direito fundamental de ser assistido por um advogado, que não leve a uma possível exclusão, de acordo com a Regra 95. O fundamento desta exclusão seriam os prejuízos causados à integridade do processo. ${ }^{36}$

É importante analisar uma outra questão, que se relaciona com a apreensão de documentos do arguido aquando da sua detenção. O mandado de detenção não permite a apreensão dos objetos que se encontrem na posse do indivíduo detido. Contudo, o Tribunal pode autorizar a sua admissibilidade, quando a detenção seja efetuada com a cooperação das autoridades dos Estados, e algumas das legislações nacionais permitam essa revista e consequente apreensão, tanto durante o ato de detenção como posteriormente. ${ }^{37}$ Mas esta questão não é pacífica, tendo sido já questionada por um dos arguidos que afirmava que a acusação não tinha solicitado a colaboração das autoridades locais, não tendo por isso apoio na legislação nacional para efetuar a apreensão de objetos aquando da detenção. ${ }^{38}$ Nesta situação, o arguido não deve ser privado de uma defesa completa, por estar em causa uma alegada violação da soberania de um Estado. ${ }^{39}$ Contudo, para que a pretensão do arguido tenha sucesso, a defesa deve provar que a acusação estava obrigada a solicitar a cooperação das autoridades locais, mas também que esta não solicitação coloca sérias dúvidas sobre a credibilidade da prova ou que a sua admissão causaria sérios danos à integridade do processo. ${ }^{40}$

Não obstante, após rever os argumentos do arguido, o Tribunal de Recurso considerou que a defesa não conseguiu demonstrar o nexo de causalidade entre a não solicitação de cooperação das autoridades locais e a credibilidade da prova obtida e se esse comportamento antiético afetaria a integridade do processo. ${ }^{41}$

Uma outra situação passível de contender com as proibições de prova são as comunicações, ou seja, as matérias relacionadas com o sempre controverso âmbito das escutas

35 Prosecutor v. Martic, Case No. IT-95-11-T, 19 January 2006, p. 6.

36 Ver no mesmo sentido: Prosecutor v. Zigiranyirazo, Case No. ICTR-2001-73-T, 29 November 2006, § 13; Prosecutor v. Delalic et al., Case No. IT-96-21-T, 2 September 1997, § 43.

37 Prosecutor v. Muvunyi, Case No. ICTR-2000-52A-T, 26 April 2006, § 24.

38 Prosecutor v. Naletilic and Martinovic, Case No. IT-98-34-A, 3 May 2006, § 238.

39 Idem.

40 Idem.

41 Ibidem. 
telefónicas. Como é sabido, esta prática responde a regras e requisitos formais e o problema não se coloca quanto a isso. Os problemas surgem quando estão em causa as «esferas de segredo ou das relações de confiança» ${ }^{42}$ que as leis internacionais têm definido como uma área de tutela. Neste sentido consideramos que as comunicações entre advogado e cliente, entre médico e paciente e entre assistente religioso e arguido devem ser tidas como privilegiadas. Por esse facto, não podem ser utilizadas em julgamento, logo não devem ser admitidas como prova.

Dos privilégios mencionados, o único que se encontra expressamente previsto na Regra 97 do Regulamento Processual do TPIJ é o privilégio entre advogado e cliente. O fundamento deste privilégio prende-se com a necessidade de lealdade entre advogado e cliente. Por conseguinte, as comunicações entre advogado e cliente não estão sujeitas a revelação. Este privilégio é muito característico dos sistemas adversariais em que o advogado representa e é a voz do seu cliente. Ao contrário do que parece decorrer dos sistemas da Common Law em que este privilégio tem apenas uma direção (cliente-advogado), a Regra 97 evidencia duas direções, ou seja, protegem-se as comunicações do cliente com o advogado, mas também do advogado com o cliente. ${ }^{43}$

«Embora a Regra 97 do Regulamento Processual do TPIJ defina os detalhes deste privilégio, desta previsão sobressaem principalmente as suas omissões. Por exemplo, esta Regra não especifica se as comunicações entre o arguido e os outros membros do staff de defesa estão protegidas.» ${ }^{44} \mathrm{O}$ caso paradigmático que trata esta matéria é o caso Prlic, em que a acusação solicitou ao Tribunal de Recurso que revogasse a decisão anteriormente tomada e seguisse a jurisprudência do próprio Tribunal e limitasse os contactos entre o arguido e o seu advogado enquanto o arguido presta depoimento como uma testemunha, consequentemente sob juramento, à luz da Regra $85(\mathrm{C}) .{ }^{45}$ Com esta interpelação o Tribunal de Recurso resolve definir os limites que regulam as comunicações entre arguido e advogado, quando aquele presta testemunho no âmbito da Regra 85(C). Esta Regra permite que os arguidos possam aparecer como testemunhas na sua própria defesa. Todavia, o Tribunal de Recurso tal como o Tribunal de 1. Instância sustentaram que há diferenças entre os depoimentos de testemunhas e de arguidos. Mesmo nesta situação o arguido conserva todos os direitos que lhe são atribuídos pelo Estatuto e pelo Regulamento Processual, nomeadamente o direito a ser assistido por um advogado à sua escolha. ${ }^{46} \mathrm{Na}$ decisão que se pretende impugnar, o Tri-

43 Khan, Karim A. A. and Others; 2010; p. 586.

44 Idem.

45 Prosecutor v Prlic et al., Decision Appeal Chamber, 5 September 2008, § 2 e 10.

$46 \mathrm{Idem}, \S 3$ e 11. 
bunal de $1 .{ }^{a}$ Instância defendeu que a proibição de contacto entre as testemunhas e as partes não é, per se, aplicável às comunicações entre o arguido e o seu advogado e o Tribunal de Recurso segue a mesma orientação. ${ }^{47}$ Importa ressalvar que no geral tendemos a concordar com as decisões destes Tribunais, contudo, tal como sublinham os Juízes Shahabuddeen e Vaz apesar de ser permitida a comunicação, o advogado não pode instruir o arguido nas respostas o que podem é ter conversas «apropriadas». ${ }^{48}$

«O equilíbrio entre o direito fundamental dos arguidos a serem assistidos por um defensor em qualquer fase do processo e a proteção das comunicações entre advogado e cliente pode levantar outras questões. Por exemplo, o arguido pode sugerir tópicos que o seu defensor pode não ter considerado nos interrogatórios ou levantar questões que precisam de ser tratadas durante o seu depoimento no tribunal.»49

Por outro lado, a própria defesa pode adotar a estratégia de limitar as comunicações entre o arguido e o seu defensor enquanto aquele presta testemunho para evitar que o Tribunal duvide da espontaneidade e da veracidade das suas respostas..$^{50} \mathrm{Uma}$ destas situações sucedeu no caso Prlic em que o defensor do arguido Praljak decidiu voluntariamente cessar o contacto com o arguido, exceto em matérias laterais, mas que não estivessem relacionadas com o testemunho. ${ }^{51}$

Todavia esta matéria levanta a questão de saber quais são as comunicações que estão protegidas por este privilégio. O TPIJ tem considerado que muitas comunicações não estão protegidas, nomeadamente o Tribunal de Recurso no caso Tadic sustentou que este privilégio não englobava os depoimentos das testemunhas prestados anteriormente. ${ }^{22}$ Mais tarde, esta situação teve previsão legal na Regra 67 (A) do Regulamento Processual ao prever-se que a defesa deveria revelar à acusação cópias dos depoimentos de todas as testemunhas que a defesa fazia intenção de inquirir no julgamento.

Em síntese, podemos concluir que este privilégio diz respeito, principalmente, a comunicações e documentos que tenham o propósito de fornecer assistência legal ao arguido, não abrangendo todas as comunicações.

47 Idem, § 12.

48 Idem, Joint Declaration of Judge Shahabuddeen and Judge Vaz.

49 Khan, Karim A.A. and Others; 2010; p. 590.

50 Idem.

51 Prosedutor v. Prlic et al., Case No. IT-04-74-T, Transcript of 13 July 2009.

52 Prosecutor v. Tadic, Case No. IT-94-1-A, Appeal Chamber Judgment, 15 July 1999, §§ 325-326. Ver também declaração de voto do Juiz Shahabuddeen. 
Quanto às outras comunicações no âmbito de relações de confiança, os Estatutos dos Tribunais Ad Hoc não reconhecem nenhum privilégio às comunicações entre médico e paciente, ${ }^{53}$ nem mesmo entre assistente religioso e arguido. Como veremos, esta é uma matéria que foi muito desenvolvida no contexto do Tribunal Penal Internacional (TPI).

No âmbito da valoração da prova, o alcance da Regra 95 do Regulamento Processual do TPIJ é muito vasto. No caso Delalic, o Tribunal «considerou que todas as provas que sejam credíveis e tenham valor probatório são admissíveis. Para que uma prova seja considerada como credível deve relacionar-se com a matéria do processo em causa e tem de ter sido obtida sob determinadas circunstâncias, que não deixem dúvidas sobre a sua natureza e qualidade e que não tenham violado quaisquer direitos fundamentais dos arguidos». Concretiza-se esta situação se a prova tiver sido obtida de acordo com os parâmetros da Regra 95 do Regulamento Processual, ou seja, através de métodos que não causem prejuízos graves à integridade dos procedimentos. Não existem quaisquer dúvidas que os depoimentos obtidos de forma não voluntária, ou que somente aparentemente são obtidos de forma voluntária, mas que na realidade o foram através de métodos opressivos, se enquadram na Regra 95 do Regulamento Processual. Um outro elemento que consta da Regra 95 é a integridade, que é a base de um julgamento justo.

No que diz respeito aos depoimentos dos arguidos, a acusação tem de provar de forma convincente e para que não restem quaisquer dúvidas que o depoimento foi feito voluntariamente. Caso contrário, como se infere do caso Delalic, este depoimento não pode ser admitido com base na Regra 95. O mesmo sucede com os depoimentos prestados voluntariamente, mas obtidos através de meios coercivos..$^{54}$ Ainda tendo em conta a Regra 95, há certas provas, tal como aquelas que foram obtidas numa busca policial ${ }^{55}$, durante uma investigação irregular ${ }^{5-57}$, ou simplesmente se tiver existido uma violação do Regulamento Processual, que serão consideradas inadmissíveis. As irregularidades verificadas durante o processo serão suficientes para excluir as provas obtidas. Parece-nos que a Regra 95 é abrangente o suficiente para sancionar condutas incorretas ou negligentes dos investigadores, sendo ou não o Tribunal responsável pelos seus atos.

53 Neste âmbito é relevante analisar o caso Prosecutor v. Furundzija, Case No. IT-95-17/1, em que o Tribunal de 1. ${ }^{a}$ Instância reabriu o caso para que fossem revelados à defesa todos os documentos médicos de uma das testemunhas que teriam levado à condenação do arguido. Todavia, apesar do acompanhamento medico de que a testemunha necessitava porque sofria de Stress Pós Traumático, o Tribunal considerou que ela poderia gerar prova credível. Sem embargo, muitas foram as vozes que criticaram esta decisão de revelar material médico. Decision 16 July 1998; Judgment, 10 December 1998, §§ 109-113.

54 Prosecutor v. Delalic et al., 2 September 1997, §§ 41-42.

55 Prosecutor v. Kordic and Cerkez, 25 June 1999.

56 Prosecutor v. Delalic et al., 25 September 1997, § 45.

57 Prosecutor v. Delalic et al., 16 November 1998, § 65. 
Contudo, numa outra decisão do TPIJ, também no caso Delalic, o Tribunal sustentou que estaríamos perante um obstáculo muito perigoso para a administração da justiça, se as provas que fossem relevantes e com valor probatório não pudessem ser admitidas, somente devido a uma violação, de menor importância, das regras processuais, sendo que o Tribunal não está obrigado a aplicá-las. Neste caso, o Tribunal admitiu uma série de documentos como prova em nome dos interesses da justiça.

O Tribunal reservou-se o direito de exercer a sua discricionariedade na decisão de excluir provas, sempre que forem obtidas violando os direitos humanos. ${ }^{58}$

Os criadores do Regulamento Processual escolheram especificamente não definir de forma automática a exclusão de provas ilegalmente obtidas e optaram por deixar esta matéria para ser regulamentada pelas Regras 89 e 95. Torna-se óbvio que quer nos tribunais nacionais, quer nos tribunais internacionais, não é certo que uma prova obtida de forma ilegal seja, a priori, inadmissível.

Há que ter em conta as circunstâncias da sua obtenção, bem como a credibilidade que traz ao processo. ${ }^{59}$

Somente se estes pressupostos não se verificarem e se a obtenção ilegal trouxer graves danos para o processo, ou violar os direitos fundamentais, é que deve ser excluída. Como podemos sintetizar, esta questão dá azo a muita controvérsia e mesmo perante esta explicitação é-nos difícil tomar uma posição. Se, por vezes, tendemos a concordar com o Tribunal, como no caso Delalic em que foram admitidos certos documentos porque o Tribunal considerou que tinha existido somente uma violação de menor importância das Regras Processuais; por outro lado, questionamo-nos: (1) qual a linha que delimita o que se entende por violação de menor importância; e (2) até onde pode ir a discricionariedade do Tribunal com o fundamento de que se está a beneficiar os interesses da justiça.

De facto, as nossas incertezas são muitas, mas parece-nos que nesta matéria o TPIJ alargou em demasia a admissibilidade das provas potencialmente proibidas. Concordamos que este é um poder que só pode ser atribuído aos magistrados, porque não há outra forma de regulamentar esta matéria. Não obstante, consideramos que esta discricionariedade deve ser cuidadosamente administrada.

Finalmente, é relevante fazer uma reflexão sobre a questão do respeito pela garantia do salvo-conduto. Esta garantia foi um recurso utilizado em diversas decisões do TPIJ e do TPIR. Se ponderarmos bem o conteúdo desta garantia, verificamos que ela é fundamental para que certos indivíduos se predisponham a testemunhar em Tribunal. Muitas vezes, só 
com a garantia de que não serão detidas ou capturadas é que certas pessoas se apresentam em Tribunal. O que sucedeu no caso Karadzic ${ }^{60}$, no qual a acusação solicitou ao Tribunal que concedesse a garantia de salvo-conduto à testemunha Momcilo Mandic. ${ }^{61}$ Esta testemunha já tinha beneficiado desta garantia em duas situações anteriores, mas de forma confidencial. O Tribunal considerou que a garantia de salvo-conduto é um instrumento de utilização comum no direito internacional e na prática deste Tribunal, onde se permite que seja concedida uma imunidade limitada em circunstâncias específicas, como é o caso. ${ }^{62}$ No caso Gotovina também foi utilizada a garantia do salvo-conduto para permitir o testemunho de Kosta Novakovic. Este caso tem a particularidade de primeiramente a garantia ter sido concedida como confidencial, mas depois o Tribunal ter decidido que não existiam motivos ponderáveis para que não fosse tornada pública. ${ }^{63}$ Para além destes casos, também no caso Delalic esta garantia foi concedida a oito testemunhas de um dos arguidos, Esad Landzo, consideradas como suspeitas pela acusação e que, somente se beneficiassem desta garantia, se deslocariam para depor em Tribunal. ${ }^{64}$

No TPIR esta garantia também foi utilizada no caso Nyiramasuhuko, no qual a defesa pretendia que fosse concedida uma série de medidas de proteção a uma testemunha. Esta testemunha era considerada fundamental para o processo, mas tinha uma situação bastante complexa porque, para além da garantia de salvo-conduto, residia na Bélgica e o Estado belga já tinha emitido uma ordem de expulsão que ainda não tinha sido concretizada. O Tribunal negou parte das pretensões da defesa, mas concedeu a garantia de salvo-conduto, com a ressalva de que a testemunha não poderia usar o motivo de doença para se manter na Tanzânia, e se praticasse algum ato ilícito durante esse período também não poderia invocar esta garantia. ${ }^{65}$ Finalmente, no caso Nzirorera, verifica-se também uma especificidade, considerando que o arguido pretendia que a garantia de salvo-conduto não se limitasse aos crimes que se encontravam sob a jurisdição do Tribunal. O Tribunal não concordou e rejeitou o pedido da defesa. ${ }^{66}$

Daqui decorre a incomensurável importância da garantia do salvo-conduto nos Tribunais Penais Internacionais e que em face da referida decisão do TEDH, ${ }^{67}$ pode estar em equação.

60 Prosecutor v. Radovan Karadzic, Case No. IT-95-5.

61 Idem, 16 June 2010, § 1.

62 Idem, $\S \S 7-11$.

63 Prosecutor v. Gotovina et al., Case No. IT-06-9o-T, 12 May 2009.

64 Prosecutor v. Delalic et al., Case No. IT-96-21, 25 June 1998.

65 Prosecutor v. Pauline Nyiramasuhuko, Case No. ICTR-97-21-T, 17 June 2005.

66 Prosecutor v. Karemera et al., Case No. ICTR-98-44-T, 24 March 2009.

67 TEDH, Case Adamov v. Suisse; 21 Juin 2011. 


\subsubsection{Provas Obtidas por Meios Proibidos no Tribunal Penal Internacional}

Ao contrário do que sucede nos Tribunais Ad Hoc, esta matéria está expressamente prevista no Estatuto de Roma. O art. $55^{\circ}$, n. ${ }^{\circ} 1$, al. b) refere que «no decurso de um inquérito nenhuma pessoa poderia ser submetida a qualquer forma de coação, intimidação ou ameaça, tortura ou outras formas de penas ou tratamentos cruéis, desumanos ou degradantes.» Este direito constitui uma salvaguarda para que nenhuma pessoa seja sujeita a tratamentos desumanos enquanto decorrem as atividades do TPI. Por outro lado, garante-se a proteção de qualquer pessoa de sofrer atos ilegais praticados pelas autoridades que conduzem as investigações. ${ }^{68}$ Este direito está em conformidade com o direito à não autoincriminação e o direito ao silêncio.

Também neste contexto, é relevante integrar o conteúdo inerente às relações de confiança, designadamente as comunicações privilegiadas ou não entre defensor e cliente, médico e paciente e assistente religioso e arguido.

O TPI não fornece, de forma expressa, uma proteção para a relação defensor-cliente.

Diferentemente, os meandros da relação médico-paciente encontram-se tipificados na Regra 73 do Regulamento Processual do TPI, na qual se qualificam as comunicações entre estes sujeitos de privilegiadas. Por exemplo, o caso Thomas Lubanga Dyilo é pródigo em situações difíceis. Referimo-nos aos depoimentos de crianças-soldado e de vítimas de violência sexual, em que o testemunho pode ser muito traumatizante e estas podem não se encontrar em situações psicologicamente capazes. O TPI tem sustentado a necessidade de prestar apoio a estas testemunhas, incluindo aconselhamento psicológico prestado pelo TPI. ${ }^{69-70}$ A questão que se levanta é a de saber se as comunicações destas testemunhas com os profissionais médicos devem permanecer confidenciais. ${ }^{71}$

Na nossa opinião é preciso ter muito cuidado com o tratamento a atribuir a estas comunicações, que primeiramente parecem dever permanecer confidenciais, mas com fundamento na necessidade de descoberta da verdade, podem determinadas comunicações ser reveladas, em certas circunstâncias. Sendo relevadas, devem ficar sujeitas ao contraditório, respeitando os direitos dos arguidos.

68 Cassese, A. and Others; 2002; p. 1197.

69 Vd. Prosecutor v Thomas Lubanga Dyilo; Case No. ICC-01/04-01/06, Transcript of 28 January 2009 e Transcript of 29 January 2009.

70 Art. $43 .^{\circ}$ n. 6 do Estatuto de Roma - «O secretário criará, no âmbito da Secretaria, uma Unidade de Apoio às Vítimas e Testemunhas. Esta Unidade, em conjunto com o Gabinete do Procurador, adoptará medidas de proteção e dispositivos de segurança e prestará assessoria e outro tipo de assistência às testemunhas e vítimas que compareçam perante o Tribunal e a outras pessoas ameaçadas em virtude do testemunho prestado por aquelas. A Unidade incluirá pessoal especializado para atender as vítimas de traumas, nomeadamente os relacionados com crimes de violência sexual.»

71 Khan, Karim A. A. and Others; 2010; p. 594. 
Por outro lado, «nas comunicações entre assistente religioso e arguido o TPI definiu dois sistemas. Primeiro, o TPI deve prestar particular atenção às comunicações entre o arguido e o assistente religioso. Nestes casos, o TPI deve determinar ou não a verificação de um privilégio inerente a essas comunicações. Importa aqui saber se as comunicações foram ou não realizadas em confissão. $\gg^{72}$

A Regra 73 deve ser interpretada em conjugação com o art. $67 .^{\circ}$ e a Regra 63 . O que significa que não podem ser esquecidos os direitos dos arguidos, nem os seus direitos à revelação da prova. Por conseguinte, se estes privilégios excluem a admissibilidade de prova potencialmente relevante, o Tribunal deve ser cauteloso por forma a prevenir abusos. Este privilégio pode ser utilizado de forma imprópria como proteção das investigações. Todavia, este privilégio não é limitado à acusação, ele aplica-se também à defesa.

A problemática do efeito à distância é uma das questões mais relevantes neste âmbito. Esta matéria surge nos casos em que a obtenção de uma determinada prova torna possível a descoberta de novos meios de prova contra o arguido ou contra terceiro. Neste contexto, cabe questionar se a proibição de valoração que eventualmente inquine a prova primária ou direta se comunica, e em que medida, às provas secundárias ou indiretas, impondo a sua exclusão em cadeia. Como facilmente se representará, o problema ganha particular relevo prático-jurídico nas hipóteses frequentes em que a realização de buscas, apreensões, exames, detenções... ou o recurso a métodos proibidos de prova, como a tortura, levam o arguido a comprometedoras declarações autoincriminatórias.

A priori, a prova proibida contamina a restante prova se houver um nexo de dependência cronológica, lógica e valorativa entre elas.

A regra para excluir provas ilegais verifica-se em praticamente todos os sistemas, quer no sistema adversarial, quer no inquisitorial. O sistema inquisitorial realça as questões processuais, o que significa que a prova será excluída se for obtida com violação das normas processuais de justiça. Por seu lado, o sistema da Common Law realça principalmente as questões da segurança, logo, se os efeitos dos procedimentos são mais prejudiciais que o seu valor probatório, a prova não poderá ser admitida. Se a admissão da prova puser em causa a justiça do processo, também deve ser excluída, de acordo com o sistema da Common Law. ${ }^{73}$

72 Idem, p. 595.

73 Tal como refere Costa Andrade, esta questão é mais linear do lado da experiência americana. «Desde as primeiras décadas do século passado - mais precisamente desde os marcantes Silverthorne Lumber Co. v. United States (1920) e Nardone v. United States (1939) - vigora aqui, de forma tão pacífica como generalizada, o princípio do efeito à distância das exclusionary rules. Ou, na expressão cunhada pelo Justice Frankfurter, $a$ fruit of the poisonous tree doctrine. Consensual é outrossim a fundamentação para que invariavelmente apontam os tribunais e tratadistas americanos quando se interrogam sobre a intencionalidade político-criminal que 
A questão do efeito à distância não se encontra expressamente definida nos diplomas legais do TPI..$^{74}$ Todavia, o art. $69 .^{\circ}$, n. $^{\circ}$ 7, do Estatuto de Roma, prevê que não são admissíveis as provas obtidas com a violação do Estatuto. Neste sentido, parece que a prova primária obtida de forma ilegal contaminará a prova que dela deriva, mas como tudo o que não está tipificado na lei, esta interpretação é passível de alterações e adaptações caso a caso. Mais uma vez, ficará nas mãos dos juízes do TPI, que integrarão devidamente estas matérias e farão da sua jurisprudência pontos de partida para a concretização desta temática.

O TPI, no caso Bemba, defendeu que a concretização dos conceitos do art. $69 .^{\circ}$, n. $^{\circ} 7$, deve ser determinada caso a caso. O Tribunal de $1 .^{a}$ Instância considerou que a conjugação deste artigo com a Regra 71 do Regulamento Processual permite concluir que nenhuma prova é per se inadmissível. ${ }^{75}$

Ponderando a garantia do salvo-conduto, hoje, no âmbito do TPI, esta garantia está prevista no art. $26 .^{\circ}$ do Acordo realizado entre o TPI e a Holanda, o estado que recebe o Tribunal. ${ }^{76}$ Julgamos que será o TPI quem mais poderá ser alvo das consequências da decisão do $\mathrm{TEDH}^{77}$, porque o receio pode levar muitas pessoas a não se deslocarem ao Tribunal.

\section{Conclusão}

No direito internacional criminal, os direitos dos arguidos são o espelho da evolução das garantias dos direitos humanos que têm influenciado a proteção dos direitos dos arguidos durante os procedimentos judiciais. Neste contexto, é importante concluir sobre a admissibilidade ou não das provas proibidas.

A exclusão de provas ilegais acontece em praticamente todos os sistemas jurídicos. Hoje não se concebe o direito, a justiça, com a admissibilidade de provas obtidas de forma

empresta racionalidade teleológica a este regime. Apesar de tudo, a vigência desta doutrina no direito americano está longe de ser absoluta e irrestrita. Por vezes pode legitimar-se a valoração de provas secundárias sempre que elas foram ou poderiam ter sido obtidas por via autónoma e legal, à margem da exclusionary rule que impende sobre a prova primária. Tal, só ocorrerá nos casos em que a produção da prova secundária, por via independente e legal, se possa, em concreto, considerar iminente. Por outro lado, temos a experiência alemã que, num primeiro confronto, deixa sobressair a sua extrema complexidade. O que, à partida e ao contrário do que sucede com o direito americano, desaconselha o recurso a enunciados axiomáticos, tendencialmente generalizadores do género: o direito alemão não reconhece qualquer efeito à distância às proibições de prova. Com o passar dos tempos e contestando este entendimento, ganham cada vez mais peso na doutrina alemã ou autores que se pronunciam a favor de um efeito à distância das proibições de prova. Hoje, são sobretudo as soluções compromissórias ou mistas que vêm colhendo o aplauso maioritário dos autores alemães.» In Andrade, Manuel Costa de, 2006, pp. 170-182.

74 Khan, Karim and Others; 2010; p. 241.

75 Prosecutor v. Jean-Pierre Bemba Gombo, Case No. ICC-01/05-01/08, 3 May 2011, pp. 7-20.

76 Headquarters Agreement between the International Criminal Court and the Host State, 1 March 2008.

77 Vd. TEDH, Case Adamov v. Suisse; 21 Juin 2011. Decisão analisada no ponto referente às provas obtidas por meios proibidos. 
ilegal. A atualidade da jurisprudência do TEDH sobre esta matéria denota bem esse facto, visto que não se podem aceitar práticas que violam as normas de direito.

Nesta matéria, como em tantas outras, os Tribunais Internacionais são influenciados pela jurisprudência do TEDH e, em consequência, o TPIJ e o TPIR, e no mesmo sentido, o TPI, não admitem como prova a que é obtida através de métodos ilegais. Mais complexa é a questão de saber se a prova proibida contamina a restante prova que com ela tenha alguma relação de dependência. Quanto a esta problemática, analisámos uma série de teorias e de conclusões. Como supra referido, o TPIJ apresenta-nos algumas soluções para esta questão, mas ainda aguardamos que a questão se coloque ao TPI para podermos constatar qual o caminho a seguir no âmbito do direito internacional. Todavia, apraz-nos avançar com uma possível solução, que nos parece vir a ser no mesmo sentido do TPIJ. Face ao exposto, serão admitidas as provas que tenham valor probatório, mesmo que de alguma forma na sua origem esteja uma prova obtida através de meios proibidos

Podemos afirmar que os Tribunais de Nuremberga e de Tóquio não são um verdadeiro precedente em matéria de direitos dos arguidos nem mesmo na regulamentação do processo investigativo. O que sucede muito provavelmente devido à tensão que existia no pós-guerra entre as partes envolvidas no conflito, e talvez por isso estes julgamentos tenham sido tantas vezes criticados por serem a «justiça dos vencedores». ${ }^{78}$ Uma outra justificação, que pode ajudar a compreender esta lacuna em relação aos direitos dos arguidos, é a falta de Tratados Internacionais que regulassem estas matérias e que nessa altura eram ainda inexistentes.

Diferentemente dos Tribunais Militares de Nuremberga e de Tóquio, o TPIJ e o TPIR e, também, o TPI, preveem as garantias dos arguidos de forma mais aprofundada e definida.

Após esta análise, poderemos verificar que o Estatuto de Roma concretiza de forma mais clara e explícita uma aproximação quer ao adversarial, quer ao inquisitorial. Por exemplo, algumas garantias que não eram muito evidentes nos Estatutos dos Tribunais Ad Hoc tornaram-se agora mais definidas, como é o caso do direito do arguido a ser ouvido de forma justa e sem limitações ou a obrigação da acusação recolher não só provas incriminatórias, mas também provas desculpatórias. Nesta matéria, o sistema criado para regular a intervenção do TPI aproxima-se do sistema inquisitorial, no qual o interesse da justiça é a procura da verdade dos factos e não só a prova da culpa do arguido. Esta é uma característica de ambos os sistemas jurídicos onde o objetivo primordial é a descoberta da verdade, mas para se atingir essa verdade utilizam-se meios diferentes. Decorre desta ilação que o princípio da 
igualdade inerente aos tribunais referenciados alarga o seu âmbito de aplicação por forma apreender características de ambos os sistemas jurídicos de forma harmoniosa.

Por outro lado, no que diz respeito aos meios de obtenção de prova e o efeito à distância verifica-se, no sistema criminal internacional, uma aproximação ao sistema adversarial em detrimento de um sistema mais rígido que é o inquisitorial. Quanto a esta matéria há uma maior flexibilidade na admissibilidade de prova tal como sucede no sistema adversarial. Verifica-se que nestes Tribunais refletem-se ainda, ao nível dos seus Regulamentos Processuais, muitas características do sistema adversarial, principalmente, os Tribunais Ad Hoc, nos quais estas Regras foram elaboradas pelos magistrados, que na sua maioria advinham de Estados da Common Law.

\section{BIBLIOGRAFIA}

ALBUQUERQUE, Paulo Pinto de

—, 2011: Comentário do Código de Processo Penal à luz da Constituição da República e da Convenção Europeia dos Direitos do Homem, Universidade Católica.

ANDRADE, Manuel da Costa

—, 2006: Sobre as Proibições de Prova em Processo Penal, Coimbra Editora.

CASSESE, Antonio; Gaeta, Paola and Jones, Jonh R. W. D.

—, 2002: The Rome Statute of the International Criminal Court: A Commentary: Materials, Volume I and II. New York, Oxford University Press.

HARRIS, Whitney R.

-, 1999: Tyranny on Trial - The Trial of the Major German War Criminals at the End of World War II at Nuremberg, Germany, 1945-1946. Dallas, Southern Methodist University Press.

KHAN, Karim A. A.; Buismen, Caroline and Gosnell, Christopher

—, 2010: Principles of Evidence in International Criminal Justice. Oxford University Press.

MINEAR, Richard $\mathrm{H}$.

—, 2001: Victors' Justice - The Tokyo War Crimes Trial. Center For Japanese Studies The University of Michigan.

MURRAY, Juliana

—, 2010: Assessing Allegations: Judicial Evaluation of Testimonial Evidence in International Tribunals. In 10 Chicago Journal of International Law, Winter 2010. Artigo.

SILVA, Germano Marques da

-, 2000: Curso de Processo Penal, Vol. I, Editorial Verbo.

SPRECHER, Drexel A.

-, 1999: Inside the Nuremberg Trial - A Prosecutor's Comprehensive Account, Vol. I e II. Maryland, University Press of America, Inc. 


\section{JURISPRUDÊNCIA}

\section{Tribunal Europeu dos Direitos do Homem}

Adamov v. Suisse

ECHR, Judgment, 21 Juin 2011

Al-Khawaja and Tahery v. United Kingdom

ECHR, Judgment 15 December 2011

Gäfgen v. Germany

ECHR, Judgment 1 June 2010

Jalloh v. Germany

ECHR, Judgment, 11 July 2006

Othman v. United Kingdom,

ECHR, Judgment, 17 January 2012

\section{Tribunal Penal Internacional para a Ex-Jugoslávia}

Brdanin and Talic (IT-99-36)

Decision on the Defence "Objection to Intercept Evidence", 3 October 2003

Delalic and Others (IT-96-21)

- Decision on Zdavko Mucic's Motion for the Exclusion of Evidence, 2 September 1997

- Decision on the Motions for the Exclusion of Evidence by the Accused, Zejnil Delalic, 25 September 1997

- Decision on the Tendering of Prosecutor Exhibits 104-108, 9 February 1998

- Order Granting Safe Conduct to Defence Witnesses, 25 June 1998

- Judgment, 16 November 1998

Dokmanovic (IT-95-13A)

- Decision on the Motion for Release by the Accused, 22 October 1997

Furundzija (IT-95-17/1)

- Decision, 16 July 1998

Gotovina and Others (IT-01-45-PT)

- Order to Lift the Confidential Status of the Trial Chamber's Order of 3 November 2008, 12 May 2009

Karadzic, Radovan (IT-95-5)

- Decision on the Prosecution's Motion for Safe Conduct for Witness Momcilo Mandic, 16 June 2010

Kordic and Cerkez (IT-95-14/2)

- Decision Stating Reasons for Trial Chamber's Ruling of 1 June 1999 Rejecting Defence Motion to Suppress Evidence, 25 June 1999

Martic, Milan (IT-95-11)

- Decision Adopting Guidelines on the Standards the Admission of Evidence, 19 January 2006

Milosevic (IT-02-54)

- Decision on Prosecution Motion for Voir Dire Proceeding, 9 June 2005

Naletilic and Martinovic (IT-98-34)

- Appeals Chamber Judgment, 3 May 2006

Nikolic, Dragan (IT-94-2-AR73)

- Decision on Defence Motion Challenging the Exercise of Jurisdiction by the Tribunal, 9 October 2002 
Prlic and Others (IT-04-74)

- Decision on Prosecution's Appeal against Trial Chamber's Order on Contact between the Accused and Counsel during an Accused's Testimony pursuant to Rule 85(c), 5 September 2008

- Transcript, 13 July 2009

Tadic (IT-94-1)

- Appeals Chamber Judgment, 15 July 1999

\section{Tribunal Penal Internacional para o Ruanda}

Bizimungu, Casimir (ICTR-99-45)

- Decision on Prosper Mugiraneza's Renewed Motion to Exclude His Custodial Statements from Evidence, 4 December 2003

- Decision on Casimir Bizimungu, Justin Mugenzi and Jerome Bicamumpaka's Written Submissions Concerning the Issues Raised at the Hearing of 31 March 2006 in Relation to the Cross Examination of Witness Augustin Kayinamura, 1 November 2006

Kabiligi and Ntabakuze (ICTR-97-34-I \& ICTR-97-30-I)

- Decision on the Defence Motion to Lodge Complaint and Open Investigations into Alleged acts of Torture Under Tules 40 (C), 6 October 1998.

Karemera and Others (ICTR-98-44)

- Decision on Joseph Nzirorera's Motion for Reconsideration of Certificate of Safe Conduct, 24 March 2009

Muvunyi (ICTR-2000-52A)

- Decision on Prosecution's Motion Pursuant to Trial Chamber's Directives of 7 December 2005 for Verification of the Authenticity of Evidence Obtained out of Court Pursuant to Rules 89(C) \& (D), 26 April 2006

Nyiramasuhuko, Pauline and Ntahobali, Arsène Shalom (ICTR-97-21)

- Decision on Nyiramasuhuko's Strictly Confidential Ex-Parte-Under Seal - Motion for Additional Protective Measures for Defence Witness WBNM, 17 June 2005

Zigiranyirazo (ICTR-2001-73-T)

- Decision on the Voir Dire Hearing of the Accused's Curriculum Vitae, 29 November 2006

\section{Tribunal Penal Internacional}

Jean-Pierre Bemba Combo (ICC-01/05-01/08OA3)

- Judgment on the Appeals of Mr. Jean-Pierre Bemba Gombo and the Prosecutor Against the Decision of Trial Chamber III entitled "Decision on the Admission into Evidence of Materials Contained in the Prosecution's List of Evidence", 3 May 2011

Thomas Lubanga Dyilo (ICC-01/04-01/06)

- Transcript, 28 January 2009 